\title{
PENGARUH UMUR, MASA KERJA, DAN PEMAKAIAN APT TERHADAP AMBANG PENDENGARAN TENAGA KERJA KONSTRUKSI KAPAL
}

Alda Chelsia R*, Hadi Suryono, Demes Nurmayanti

Jurusan Kesehatan Lingkungan, Politeknik Kesehatan Kemenkes Surabaya

*Email korespondensi: Aldadhera11@gmail.com

\begin{abstract}
ABSTRAK
Pendengaran tenaga kerja dapat terganggu akibat yang ditimbulkan dari suara-suara bising yang ada disuatu mesin perusahaan atau aktivitas pekerjaan perusahaan. Umur, masa kerja dan pemaiakan alat pelindiung pendengaran dapat mempengaruhi efektivitas pendengaran tenaga kerja. Tujuan dari penelitian ini adalah untuk mengetahui pengaruh umur, masa kerja dan pemakaian alat pelindung telinga tenaga kerja pada bagian Konstruksi.

Jenis penelitian ini menggunakan observasional analitik dengan pendekatan chi square. Variabel yang diukur pada penelitian ini adalah faktor-faktor risiko intensitas kebisingan, karakteristik individu berupa umur, masa kerja dan pemakaian APT terhadap efek pendengaran tenaga kerja.

Hasil uji intensitas kebisingan, umur, dan pemakaian APT dengan mendapatkan hasil nilai $\mathrm{p}>0,05$ menunjukkan tidak ada pengaruh terhadap ambang pendengaran. Sedangkan uji masa kerja dengan mendapatkan hasil nilai $p=0,03(<0,05)$ menunjukkan adanya pengaruh terhadap ambang pendengaran.

Saran yang dapat diampaikan pada perusahaan agar melakukan manajemen terhadap pengendalian kebisingan baik melalui administrative maupun teknis.
\end{abstract}

Kata Kunci : Intensitas Kebisingan, Pemakaian APT, Ambang Pendengaran

\section{PENDAHULUAN}

Menurut Undang-Undang Kesehatan No. 36 Tahun 2009 sehat adalah keadaan sejahtera yang meliputi seluruh badan, jiwa, dan sosial sehingga memungkinkan setiap orang dapat hidup produktif secara sosial dan ekonomi. Hal ini berarti kesehatan seseorang berperan penting untuk menunjang produktifitas orang tersebut dalam hidupnya, seperti halnya tenaga kerja disuatu tempat kerja pasti sangat mementingkan keselamatan dan kesehatan kerja oleh sebab itu tenaga kerja tersebut seharusnya mendapatkan perlindungan dari gangguan kesehatan di suatu tempat kerja.

Menurut Peraturan Menteri Kesehatan R.I Nomor 70 Tahun 2016 tentang Standar dan Persyaratan Kesehatan Lingkungan Kerja Industri, Kesehatan Lingkungan Kerja Industri adalah upaya pencegahan penyakit dan/atau gangguan kesehatan dari faktor risiko lingkungan kerja industri yang terdiri dari faktor bahaya fisik, kimia, biologi, ergonomi, dan sanitasi untuk mewujudkan kualitas lingkungan kerja industri yang sehat.
Kesehatan pada tenaga kerja sangat penting agar tenaga kerja tersebut dapat melakukan pekerjaannya dengan nyaman dan cepat, jika kesehatan tenaga kerja terganggu maka pekerjaan tenaga kerja tersebut terganggu. Masalah yang sering terjadi terhadap kesehatan tenaga kerja salah satunya yaitu pendengaran pada tenaga kerja. Pendengaran tenaga kerja terganggu dapat saja terjadi akibat yang ditimbulkan dari suara-suara bising yang ada disuatu mesin perusahaan atau aktivitas pekerjaan perusahaan.

Kebisingan adalah semua suara yang tidak dikehendaki yang bersumber dari alat proses produksi dan atau alat kerja yang pada tingkat tertentu dapat menimbulkan gangguan pada pendengaran (Peraturan Menteri Tenaga Kerja dan Transmigrasi RI No 13 tahun 2011). Efek bising terhadap pendengaran dapat dibagi menjadi tiga kelompok, yaitu trauma akustik, perubahan ambang pendengaran akibat bising yang berlangsung sementara (noise-induced temporary threshold shift) dan perubahan ambang pendengaran akibat bising yang berlangsung permanen (noiseinduced 
permanent threshold shift). Menurut Peraturan Menteri Kesehatan R.I Nomor 70 Tahun 2016 tentang Standar dan Persyaratan Kesehatan Lingkungan Kerja Industri, Nilai ambang batas kebisingan disuatu tempat kerja sebesar $85 \mathrm{~dB}(\mathrm{~A})$ untuk 8 jam kerja perhari. Nilai ambang batas kebisingan tersebut merupakan nilai yang mengatur tentang tekanan bising rata-rata berdasarkan durasi pajanan bising yang mewakili kondisi dimana hampir semua tenaga kerja terpajan bising yang berulang tanpa menimbulkan gangguan pendengaran dan memahami pembicaraan normal. Jika pendengaran tenaga kerja terganggu maka pekerjaan yang dilakukan tenaga kerja tersebut akan kurang optimal oleh sebab itu upaya kesehatan kerja ditujukan untuk melindungi pekerja agar hidup sehat dan terbebas dari gangguan kesehatan serta pengaruh buruk yang diakibatkan oleh pekerjaan maka dari itu pengelola tempat kerja wajib bertanggung jawab terhadap kesehatan dan melakukan segala bentuk upaya kesehatan melalui upaya pencegahan, peningkatan, pengobatan, dan pemulihan kesehatan bagi tenaga kerja.

Upaya kesehatan kerja dalam menangani masalah pendengaran diantaranya dapat memakai Alat Pelindung Telinga berupa earmuffdan ear plug, memakai alat peredam suara pada bangunan dan mesin, serta menanam pohon agar dapat mengurangi kebisingan pada mesin yang sedang digunakan akan tetapi masih ada tenaga kerja yang tidak memakai APT.

PT. PAL Indonesia adalah Badan Usaha Milik Negara yang bergerak di bidang industri galangan kapal. Kantor pusat dan industri galangan kapal ini terdapat di Surabaya, Jawa Timur. PT. PAL INDONESIA SURABAYA (Persero), bermula dari sebuah galangan kapal yang bernama MARINA dan didirikan oleh pemerintah Belanda pada tahun 1939. Pada masa pendudukan Jepang, Perusahaan ini beralih nama menjadi Kaigun SE 2124. Setelah kemerdekaan, Pemerintah Indonesia menasionalisasi Perusahaan ini dan mengubah namanya menjadi Penataran Angkatan Laut (PAL). Pada tanggal 15 April 1980, Pemerintah mengubah status perusahaan dari perusahaan umum menjadi perseroan terbatas sesuai dengan akta No. 12, yang dibuat oleh Notaris Hadi Moentoro, SH.

Lokasi Perusahaan di Ujung, Kota Surabaya dengan kegiatan utama memproduksi kapal perang dan kapal niaga, memberikan jasa perbaikan dan pemeliharaan kapal, serta rekayasa umum dengan spesifikasi tertentu berdasarkan pesanan.

Kemampuan rancang bangun yang menonjol dari PAL Indonesia telah memasuki pasaran internasional dan kualitasnya telah diakui dunia. Kapalkapal produksi PAL Indonesia telah melayari perairan di seluruh dunia.

Hasil survey pendahuluan yang dilakukan pada bulan Januari 2018 menyebutkan bahwa pada bagian Hull Construction divisi kapal perang menunjukkan hasil yang kurang memenuhi syarat yaitu sebesar $86 \mathrm{~dB}(\mathrm{~A})$ di bagian Assembly pada alat kerja yang berarti pada ruang kerja tersebut melebihi nilai ambang batas dengar (NAB) yang dapat berisiko menimbulkan gangguan kesehatan pendengaran bagi tenaga kerja. Hal tersebut dapat diatasi dengan meminimalisir risiko kebisingan, mengurangi paparan bising, menyediakan pelindung pendengaran, dan menyediakan alat untuk mengetahui berapa intensitas kebisingan di setiap ruangan.

Terdapat 14 tenaga kerja yang mengalami gangguan kesehatan pendengaran. Gangguan kesehatan pendengaran dipengaruhi oleh kebisingan. Penurunan daya pendengaran akibat kebisingan pada umumnya terjadi secara perlahan dalam waktu yang lama dan tanpa disadari, besarnya risiko penurunan daya pendengaran ini berbanding lurus dengan besarnya intensitas kebisingan dan lama pemaparannya sehingga mengurangi faktor yang menjadi salah satu upaya untuk mengurangi risiko peenurunan daya pendengaran tersebut. (Sasongko,2000). Tujuan dari penelitian ini untuk mengetahui pengaruh, umur, masa kerja dan penggunaan alat pelindung pendengaran terhadap ambang pendengaran pekerja. 


\section{METODE PENELITIAN}

Penelitian ini menggunakan jenis penelitian survei analitik. Suvei analitik adalah survei atau penelitian yang mencoba menggali bagaimana dan mengapa fenomena kesehatan itu terjadi kemudian melakukan analisis dinamika korelasi antara faktor resiko deskriptif atau disebut juga penelitian penjelasan. Penelitian analitik ini menggunakan jenis rancangan survei cross sectional yang mempelajari tentang dinamika korelasi antara faktor-faktor risiko dengan efek melalui cara pendekatan, pengumpulan data sekaligus pada suatu saat yaitu mengetahui hubungan antara intensitas kebisingan, karakteristik individu berupa umur, masa kerja dan pemakaian APT dengan ambang pendengaran.

\section{HASIL DAN PEMBAHASAN}

Hasil uji terhadap karakteristik individu didapatkan dari penilaian intensitas kebisingan tenaga kerja, umur, masa kerja dan pemakaian APT pada masingmasing kelompok. Berikut hasilnya :

\section{a. Karakteristik Individu}

Intensitas kebisingan adalah adanya suara-suara yang memiliki macam-macam tingkatan yang dapat mempengaruhi kebisingan dalam suatu area. Berdasarkan hasil yang telah didapatkan dari 36 tenaga kerja, terdapat $66,7 \%$ yang mempunyai intensitas kebisingan $\leq 85 \mathrm{~dB}(\mathrm{~A})$ di masing-masing bagian bengkel dapat dijelaskan bahwa Menurut Peraturan Menteri Kesehatan R.I Nomor 70 Tahun 2016 tentang Standart dan Persyaratan Kesehatan Lingkungan Kerja Industri didapatkan NAB kebisingan untuk 8 jam kerja per hari adalah sebesar $85 \mathrm{~dB}(\mathrm{~A})$.

\section{b. Umur}

Umur adalah satuan waktu yang mengukur waktu keberadaan suatu benda atau makhluk hidup baik yang hidup maupun yang mati (Depkes R.I, 2009). Berdasarkan hasil yang telah didapatkan dari 36 Tenaga Kerja, terdapat $89,9 \%$ yang mempunyai umur $\leq 40$ tahun dapat dijelaskan bahwa menurut Siswanto (1987) semakin tua umur seseorang maka akan semakin besar tingkat kelelahan yang akan dialami karena umur dapat mempengaruhi kelelahan pada pekerja.
Orang yang lebih tua memerlukan waktu yang lebih lama untuk mengembalikan suhu tubuh menjadi normal setelah terpapar aktivitas di lingkungan kerja. Denyut nadi maksimal dari kapasitas kerja yang maksimal berangsur-angsur menurun sesuai dengan bertambahnya umur. Fungsi faal tubuh berubah karena faktor umur mempengaruhi ketahanan tubuh dan kapasitas kerja bagi tenaga kerja.

\section{c. Masa Kerja \\ Masa kerja merupakan salah satu} faktor yang dapat mempengaruhi kemampuan seseorang, dengan cara melihat masa kerjanya kita dapat mengetahui seberapa lama seseorang telah bekerja dan kita dapat menilai sejauh mana pengalamannya. (Bachori, 2006). Berdasarkan hasil yang telah didapatkan dari 36 Tenaga Kerja, terdapat $5 \%$ yang mempunyai masa kerja $\leq 10$ tahun dapat dijelaskan bahwa seorang tenaga kerja yang lebih lama memiliki masa kerja maka pengalaman tenaga kerja tersebut lebih banyak akan tetapi terdapat faktor-faktor yang dapat mempengaruhi tenaga kerja.

\section{d. Pemakaian APT}

Pemakaian alat pelindung telinga digunakan untuk melindungi telinga dari suara gemuruhnya mesin yang dapat menim bulkan kebisingan juga sebagai alat untuk menahan bising dari letupanletupan. Berdasarkan hasil yang telah didapatkan dari 36 Tenaga Kerja, terdapat $39,9 \%$ yang tidak memakai alat pelindung telinga dapat dijelaskan bahwa bagi mereka yang beraktivitas di dekat peralatan atau objek yang menghasilkan bunyi-bunyi yang dapat mengganggu organ pendengaran, pemakaian alat pelindung telinga sangat disarankan dari mulai pelindung telinga yang terkecil yang dapat dimasukan ke lubang telinga (baik yang sekali pakai maupun yang dapat digunakan kembali) sampai alat pelindung yang berukuran sedang seperti headphone. 


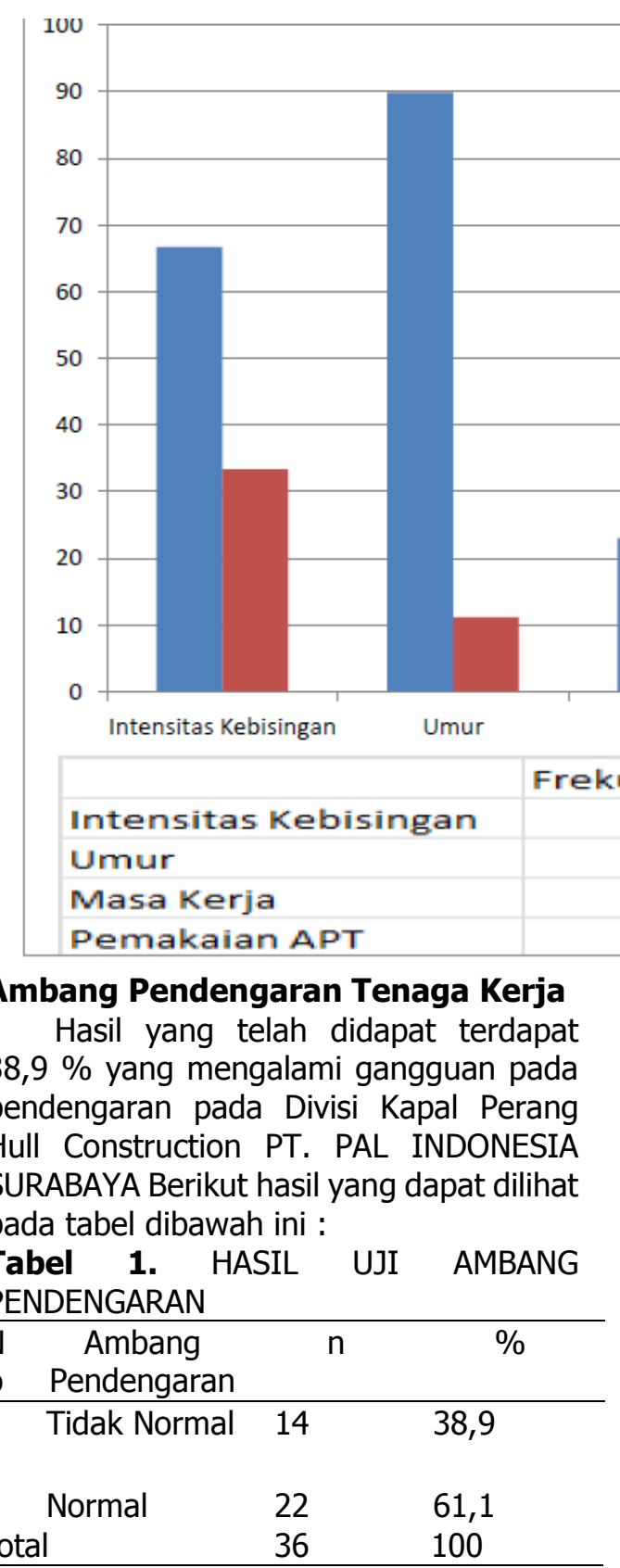

Menurut ummi iannatul (2011) bahwa ambang pendengaran adalah suara terendah yang masih dapat didengar oleh tenaga kerja. Dari tabel tersebut dapat dijelaskan bahwa semakin rendah tingkat suara yang terlepas dapat didengar maka semakin rendah nilai ambang pendengaran hal ini berarti semakin baik telinganya.

\section{Pengaruh Intensitas Keebisingan Terhadap Ambang Pendengaran}

Hasil yang telah didapatkan dari 36 Tenaga Kerja, terdapat 27,8 \% memiliki intensitas kebisingan di masing-masing

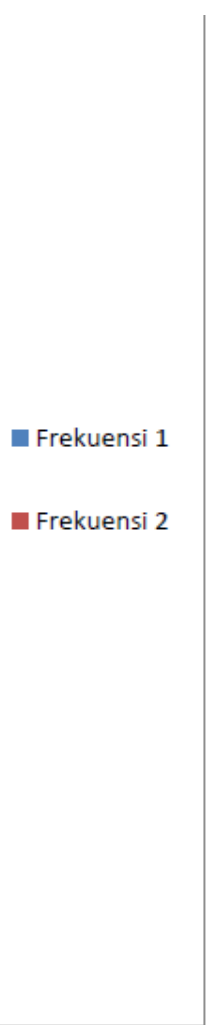

bagian bengkel $>85 \mathrm{~dB}(\mathrm{~A})$ yang dapat mempengaruhi gangguan pada pendengaran.

Hasil uji statistik chi square yang digunakan pada program SPSS versi 16.0 didapatkan hasil nilai $\rho_{\text {value }}=0,33(>0.05)$ maka $\mathrm{H}_{0}$ diterima yang berarti ada pengaruh yang signifikan umur dengan ambang pendengaran tenaga kerja bagian Hull Construction Divisi Kapal Perang di PT. PAL INDONESIA SURABAYA TAHUN 2018.

Untuk mengetahui intensitas kebisingan yang ada di masing-masing bagian bengkel maka dilakukan pengukuran. Dari hasil yang telah dilakukan pengukuran didapatkan hasil Assembly 1 sebesar 76,9 dB(A), Assembly sebesar 83,8 dB(A), bengkel Cat sebesar 70,7 dB(A), Las $\mathrm{HC}$ sebesar $89,6 \mathrm{~dB}(\mathrm{~A})$ dan pada Erection sebesar $81,5 \mathrm{~dB}(\mathrm{~A})$.

Terdapat faktor-faktor yang tidak mempengaruhi intensitas kebisingan terhadap ambang pendengaran diantaranya yaitu perusahaan sudah melakukan program pencegahan dengan cara monitoring paparan bising dan melakukan kontrol pada mesin, dan ketepatan penggunaan alat pelinung telinga. (Gunara, 2011). 


\section{Pengaruh Umur Terhadap Ambang Pendengaran}

Hasil yang telah didapatkan dari 36 Tenaga Kerja, terdapat 36,1\% memiliki umur $\leq 40$ tahun yang mengalami gangguan pada pendengaran dengan kategori tidak normal. Yang dapat dilihat pada tabel dibawah ini :

Tabel 1. HASIL UJI PENGARUH UMUR TERHADAP AMBANG PENDENGARAN

\begin{tabular}{|c|c|c|c|c|c|c|}
\hline \multirow{3}{*}{ Umur } & \multicolumn{4}{|c|}{$\begin{array}{c}\text { Ambang } \\
\text { Pendengaran }\end{array}$} & \multirow{2}{*}{\multicolumn{2}{|c|}{ Total }} \\
\hline & \multicolumn{2}{|c|}{$\begin{array}{c}\text { Tidak } \\
\text { Normal }\end{array}$} & \multicolumn{2}{|c|}{ Normal } & & \\
\hline & $\mathrm{n}$ & $\%$ & $\mathrm{n}$ & $\%$ & $\mathrm{~N}$ & $\%$ \\
\hline \begin{tabular}{|l|}
$\leq 40$ \\
Tahun
\end{tabular} & 13 & 36,1 & 19 & 52,8 & 32 & 88,9 \\
\hline \begin{tabular}{|l|}
$>40$ \\
Tahun
\end{tabular} & 1 & 2,8 & 3 & 8,3 & 4 & 11,1 \\
\hline Total & 14 & 38,9 & 22 & 61,1 & 36 & 100 \\
\hline$\alpha=0$, & & & & $=$ & 0,54 & \\
\hline
\end{tabular}

Untuk mengetahui umur tenaga kerja maka dilakukan wawancara kepada tenaga kerja dengan mengisi kuisioner (lembar isian data) dan dari hasil pengukuran yang dilakukan oleh petugas UPTK3 Surabaya. Dari hasil tersebut diketahui tenaga kerja yang mempunyai umur antara 22-40 tahun yang bekerja dibagian Hull Construction. Sedangkan untuk pengukuran nilai ambang dengar dilakukan dengan menggunakan alat audiometer di ruang K3 yang dilaksanakan pemeriksaan berturut-turut dari frekuensi pembicaraan dan frekuensi tinggi antara 0,25, 0,5, 1, 2, $3 \mathrm{KHz}$ yang didapatkan masing-masing rata-ratanya

Hasil penelitian menunjukan bahwa umur tenaga kerja tidak mempunyai pengaruh yang signifikan dengan ambang pendengaran. Terdapat faktor yang tidak mempengaruhi umur terhadap ambang pendengaran salah satunya yaitu jenis pekerjaan. Bila tenaga kerja bekerja mulai bekerja sejak umur 20 tahun maka tenaga kerja tersebut sudah terbiasa dengan kegiatan yang dilakukan di lingkungan kerja tersebut

\section{Pengaruh Masa Kerja Terhadap Ambang Pendengaran}

Berdasarkan hasil yang telah didapatkan dari 36 Tenaga Kerja, terdapat 36,1 \% memiliki masa kerja $\leq 10$ Tahun yang mengalami gangguan pada pendengaran dengan kategori tidak normal. Yang dapat dilihat pada tabel dibawah ini :

Tabel 2. HASIL UJI PENGARUH MASA KERJA TERHADAP AMBANG PENDENGARAN

\begin{tabular}{|c|c|c|c|c|c|c|}
\hline \multirow{2}{*}{$\begin{array}{c}\text { Masa } \\
\text { Kerja }\end{array}$} & \multicolumn{2}{|c|}{\begin{tabular}{c} 
Ambang Pendengaran \\
Tidak \\
\cline { 2 - 6 }
\end{tabular}} & \multicolumn{2}{|c|}{ Normal } & \multicolumn{2}{c|}{ Total } \\
\cline { 2 - 6 } & $\mathrm{n}$ & $\%$ & $\mathrm{~N}$ & $\%$ & $\mathrm{n}$ & $\%$ \\
\hline $\begin{array}{c}\leq 10 \\
\text { Tahun }\end{array}$ & 12 & 33,3 & 11 & 30,6 & 27 & 63,9 \\
\hline $\begin{array}{c}>10 \\
\text { Tahun }\end{array}$ & 2 & 5,6 & 11 & 30,5 & 9 & 36,1 \\
\hline Total & 11 & 38,9 & 22 & 61,1 & 36 & 100 \\
\hline$\alpha=0,05$ & \multicolumn{5}{|c|}{$\rho_{\text {value }}=0,03$} \\
\hline
\end{tabular}

Hasil uji statistik chi square yang digunakan pada program SPSS versi 16.0 didapatkan hasil nilai $\rho_{\text {value }}=0,03(\leq 0,05)$ maka $\mathrm{H}_{0}$ ditolak yang berarti ada pengaruh masa kerja dengan ambang pendengaran tenaga kerja bagian Hull Construction Divisi Kapal Perang di PT. PAL INDONESIA SURABAYA TAHUN 2018. Hasil penelitian tersebut sejalan dengan penelitian yang dilakukan oleh Sari, dkk (2012) pada tenaga kerja PT. PLN (PERSERO) wilayah Kalimantan Timur sektor Mahakam, PLTD Karang Asem Samarinda, berdasarkan uji statistik dengan menggunakan chi kuadrat didapatkan bahwa ada hubungan yang signifikan antara lama pemaparan kebisingan berdasarkan masa kerja dengan ambang pendengaran tenaga kerja yang memiliki nilai hasil sebesar $15,250>5,991$ pada taraf kesalahan 5\% dengan derajat kebebasan $=1$. Hal ini berarti semakin lama 50 tenaga kerja terpapar oleh kebisingan maka semakin 
tinggi (banyak) tenaga kerja yang mengalami gangguan pendengaran.

Hasil penelitian lainnya dari Ummi (2011), berdasarkan uji statistik Korelasi Pearson Product Moment menggunakan program SPSS versi 16.0 diperoleh hasil signifikan antara masa kerja dengan nilai ambang pendengaran telinga kiri tenaga kerja yang terpapar bising pada bagian Weaving PT. Triangga Dewi Surakarta dengan hasil nilai koefisien determinan telinga kanan sebesar $50,55 \%$ sedangkan telinga kiri sebesar $39,06 \%$. Hal tersebut menyatakan bahwa sumbangan masa kerja terhadap nilai ambang dengar.

Untuk mengetahui masa kerja tenaga kerja maka dilakukan wawancara kepada tenaga kerja dengan mengisi kuisioner (lembar isian data) dan dari hasil pengukuran yang dilakukan oleh petugas UPTK3 Surabaya. Dari hasil tersebut diketahui tenaga kerja yang mempunyai masa kerja antara 3-22 tahun yang bekerja dibagian Hull Construction . Sedangkan untuk pengukuran nilai ambang dengar dilakukan dengan menggunakan alat audiometer di ruang K3 yang dilaksanakan pemeriksaan berturut-turut dari frekuensi pembicaraan dan frekuensi tinggi antara $0,25,0,5,1,2$, $3 \mathrm{KHz}$ yang didapatkan masing-masing rata-ratanya.

Dari hasil penelitian terhadap 36 tenaga kerja diperoleh hasil bahwa untuk masa kerja $\leq 10$ tahun yang memiliki ambang pendengaran tidak normal sebesar $36,1 \%$ (10 orang) dan yang memiliki pendengaran normal sebesar $38,9 \%$ (14 orang) sedangkan masa kerja $>10$ tahun yang memiliki ambang pendengaran tidak normal sebesar 2,8\% (1 orang) dan yang memiliki pendengaran yang normal sebesar $22,2 \%$ (8 orang). Dengan demikian tenaga kerja yang lebih lama memiliki masa kerja maka pengalaman tenaga kerja tersebut lebih banyak akan tetapi terdapat faktor-faktor yang dapat mempengaruhi tenaga kerja diantaranya yaitu sikap kerja, tingkat keterampilan, hubungan antara tenaga kerja dan pimpinan organisasi, manajemen produktivitas, efisien, kewirausahaan yang tercermin dalam pengambilan risiko atau kreativitas dalam berusaha.

\section{Pengaruh Pemakaian APT Terhadap Ambang Pendengaran}

Hasil yang telah didapatkan dari 36 Tenaga Kerja, terdapat 19,4 \% tidak memakai APT yang mengalami gangguan pada pendengaran dengan kategori tidak normal. Yang dapat dilihat pada tabel dibawah ini :

\begin{tabular}{|c|c|c|c|c|c|c|}
\hline \multirow{3}{*}{$\begin{array}{c}\text { Pemakaian } \\
\text { APT }\end{array}$} & \multicolumn{4}{|c|}{$\begin{array}{c}\text { Ambang } \\
\text { Pendengaran }\end{array}$} & \multirow{2}{*}{\multicolumn{2}{|c|}{ Total }} \\
\hline & \multicolumn{2}{|c|}{\begin{tabular}{c|} 
Tidak \\
Normal
\end{tabular}} & \multicolumn{2}{|c|}{ Normal } & & \\
\hline & $\mathrm{n}$ & $\%$ & $\mathrm{n}$ & $\%$ & $\mathrm{~N}$ & $\%$ \\
\hline $\begin{array}{c}\text { Ya } \\
\text { Memakai }\end{array}$ & 9 & 25,0 & 14 & 38,9 & 23 & 63,9 \\
\hline \begin{tabular}{|c|} 
Tidak \\
Memakai
\end{tabular} & 5 & 13,9 & 8 & 22,2 & 13 & 75,1 \\
\hline Total & 14 & 38,8 & 22 & 61,2 & 36 & 100 \\
\hline$\alpha=0,05$ & & & & value $=$ & 1, & \\
\hline
\end{tabular}

Hasil uji statistik chi square yang digunakan pada program SPSS versi 16.0 didapatkan hasil nilai pvalue $=0,96$ ( > $0,05)$ maka $\mathrm{H}_{0}$ diterima yang berarti tidak ada pengaruh masa kerja dengan ambang pendengaran tenaga kerja bagian Hull Construction Divisi Kapal Perang di PT. PAL INDONESIA SURABAYA TAHUN 2018. Hasil penelitian ini tidak sejalan dengan penelitian yang dilakukan oleh Indra yang melakukan analisis regresi logistik yang diketahui bahwa variabel penggunakan alat pelindung pendengaran dan masa kerja mempunyai pengaruh yang signifikan terhadap variabel gangguan pendengaran dengan nilai koefisien 0,00 dengan keeratan hubungan antara variabel bebas dengan variabel terikat yang ditandai dengan nilai $R=0,548$ yang artinya terjadi hubungan antara kedua variabel dan presentase hubungan antara kedua variabel tersebut diperoleh nilai $\mathrm{R}$ square $-=0,757$ yang artinya $75,7 \%$ variasi terjadi pada variabel gangguan pendengaran dapat dijelaskan oleh variabel penggunaan alat pelindung pendengaran dan masa kerja. 
Untuk mengetahui pemakaian alat pelindung telinga tenaga kerja maka dilakukan wawancara kepada tenaga kerja dengan mengisi kuisioner (lembar isian data). Dari hasil tersebut diketahui tenaga kerja yang memakai alat pelindung telinga 22 orang dari 36 tenaga kerja yang bekerja dibagian Hull Construction. Sedangkan untuk pengukuran nilai ambang dengar dilakukan dengan menggunakan alat audiometer di ruang K3 yang dilaksanakan pemeriksaan berturut-turut dari frekuensi pembicaraan dan frekuensi tinggi antara 0,25, 0,5, 1, 2, $3 \mathrm{KHz}$ yang didapatkan masing-masing rata-ratanya.

Dari hasil penelitian 36 tenaga kerja yang memakai APT memiliki ambang pendengaran yang tidak normal sebesar $19,7 \%$ ( 7 orang) dan yang memiliki pendengaran normal sebesar 30,6\% (11 orang) sedangkan yang tidak memakai APT memiliki ambang pendengaran tidak normal sebesar $19,7 \%$ (7 orang) dan yang memiliki pendengaran normal sebesar 30,6 (11 orang). Dengan demikian penggunaan alat pelindung telinga tidak memiliki pengaruh signifikan terjadinya gangguan pendengaran tenaga kerja yang terpapar bising, hal tersebut dapat dipengaruhi oleh ketepatan atau kesesuaian penggunaan alat pelindung telinga berdasarkan jenisnya seperti sumbat telinga, tutup telinga dan helmet. Sumbat telinga (earplug/insert device/aural insert protector) yaitu alat yang bisa mengurangi bising sampai dengan $30 \mathrm{~dB}(\mathrm{~A})(\mathrm{A})$ yang dimasukan kedalam liang telinga sampai menutup rapat sehingga suara tidak mencapai membran timpani. Tutup telinga (earmuff/protective caps/cirmanural protector) yaitu alay yang menutupi seluruh telinga eksternal dan digunakan untuk mengurangi bising sampai dengan 40-50 dB(A)(A) dan frekuensi 100$8000 \mathrm{~Hz}$. Helmet (Enclosure) yaitu alat yang menutupi seluruh kepala dan digunakan umtuk mengurangi bising maksimum antara $35-250 \mathrm{~dB}(\mathrm{~A})(\mathrm{A})$ pada frekuensi tinggi (Gunawar, 2011).

\section{KESIMPULAN}

Hasil analisis statistik uji chi square yang digunakan pada program SPSS versi
16.0 diketahui bahwa variabel pengganggu pada masa kerja mempunyai pengaruh dengan variabel terikat pada ambang pendengaran dengan hasil nilai $p$ $\leq 0,05$ terhadap ambang pendengaran tenaga kerja pada bagian Hull Construction PT. PAL INDONESIA SURABAYA. sehingga dapat disimpulkan bahwa ada hubungan yang sangat signifikan. Sedangkan variabel terikat pada pemakaian APT tidak memiliki pengaruh yang signifikan pada variabel bebas pada intensitas kebisingan dengan variabel pengganggu pada umur dan pemakaian APT dengan hasil nilai $p=0,96$ ( $>$ 0.05) pada bagian Hull Construction PT. PAL INDONESIA SURABAYA.

\section{SARAN}

Sebaiknya perusahaan menyediakan ruangan khusus (ruangan kedap suara) karena ruangan kedap suara tersebut masih bisa mendengar suara bising (kegiatan bising) tersebut. Tenaga kerja membiasakan diri dan disiplin untuk menggunakan alat pelindung telinga di tempat kerja baik saat melakukan pekerjaan bising maupun saat tidak melakukan pekerjaan bising agar tidak terpajan area bising.

\section{DAFTAR PUSTAKA :}

Khakim ianatul ummi. (2011). Hubungan masa kerja dengan nilai ambang dengar tenaga kerja yang terpapar bising pada bagian weaving di PT. Triangga Dewi. Surakarta : paparan bising. From https://digilib.uns.ac.id/dokumen /download/22928/NDgyMDI=/Hu bungan-Masa-Kerja-DenganNilai-Ambang-Dengar-TenagaKerja-Yang-Terpapar-BisingPada-Bagian-Weaving-Di-PtTriangga-DewiSurakartaabstrakpdf.

Peraturan Undang-Undang Kesehatan No. 36 Tahun 2009 tentang kesehatan. (2009). Kesehatan. From http://www.depkes.go.id/resourc es/download/general/UU\%20No mor\%2036\%20Tahun2\%20009 \%20tentang\%20Kesehatan.pdf. 
Peraturan Menteri Tenaga Kerja dan Transmigrasi R.I Nomor 13 Tahun 2011 tentang nilai ambang batas faktor fisika kimia. (2011). Nilai Ambang Batas Faktor Fisika Kimia. From

http://ditjenpp.kemenkumham.g o.id/arsip/bn/2011/bn6842011.pdf.

Peraturan Menteri Kesehatan R.I Nomor 70 Tahun 2016 tentang Standar dan Persyaratan Kesehatan Lingkungan Kerja Industri. (2016). Standar dan Persyaratan Kesehatan Lingkungan Kerja Industri. From

http://www.kesjaor.kemkes.go.id Ldocuments/PMK No. $70 \mathrm{ttg} \mathrm{St}$ andar Kesehatan Lingkungan $\mathrm{K}$ erja Industri .pdf.
Sasongko., D.P., dkk. 2000. Kebisingan Lingkungan. Semarang Universitas Dipenogoro.

Siswanto. 1987. Tekanan Panas. Surabaya : Balai Hiperkes dan Keselamatan Kerja Jawa Timur. 